\title{
Potential Impact of Graphic Health Warnings on Cigarette Packages in Reducing Cigarette Demand and Smoking-Related Deaths in Vietnam
}

\author{
Hoang Van Minh ${ }^{1 *}$, Le Hong Chung${ }^{1}$, Kim Bao Giang², Duong Minh Duc ${ }^{1}$, \\ Nguyen Duc Hinh ${ }^{2}$, Vu Quynh Mai ${ }^{1}$, Nguyen Manh Cuong ${ }^{3}$, Pham Duc Manh ${ }^{3}$, \\ Ha Anh Duc ${ }^{3}$, Jui-Chen Yang ${ }^{4}$
}

\begin{abstract}
Two years after implementation of the graphic health warning intervention in Vietnam, it is very important to evaluate the intervention's potential impact. The objective of this paper was to predict effects of graphic health warnings on cigarette packages, particularly in reducing cigarette demand and smoking-associated deaths in Vietnam. In this study, a discrete choice experiment (DCE) method was used to evaluate the potential impact of graphic tobacco health warnings on smoking demand. To predict the impact of GHWs on reducing premature deaths associated with smoking, we constructed different static models. We adapted the method developed by University of Toronto, Canada and found that GHWs had statistically significant impact on reducing cigarette demand (up to $10.1 \%$ through images of lung damage), resulting in an overall decrease of smoking prevalence in Vietnam. We also found that between 428,417- 646,098 premature deaths would be prevented as a result of the GHW intervention. The potential impact of the GHW labels on reducing premature smoking-associated deaths in Vietnam were shown to be stronger among lower socio-economic groups.
\end{abstract}

Keywords: Graphic health warnings - impact - cigarette demand - mortality- Vietnam

Asian Pac J Cancer Prev, 17 Tobacco Prevention and Control in Vietnam Suppl, 85-90

\section{Introduction}

Graphic health warnings (GHW) on tobacco packages are among the most direct and prominent means to increase consumer knowledge of the health risks and dangers related to tobacco use, encourage cessation and discourage uptake or relapse (Hammond, 2011; Thrasher et al., 2011). The World Health Organization Framework Convention on Tobacco Control (WHO FCTC), in Article 11 , states that "each party will implement effective health warnings, including pictograms, on the packaging of all products of tobacco use within three years of adoption of the FCTC" (World Health Organization, 2003; World Health Organization, 2008). MPOWER, a WHO intervention strategy that concretizes the WHO FCTC recommendations, concludes that "Health warnings on tobacco packaging reach all smokers and cost governments nothing... Pictures of diseases have a greater impact than words alone" (World Health Organization, 2008).

In line with the global effort to tackle the smoking epidemic, the Government of Vietnam implemented several measures to discourage smoking. A comprehensive national tobacco control law in Vietnam, the Law on Prevention and Control of Tobacco Harms, was enacted in June 2012 and was taken into effect on May 1, 2013, and its contents specifies "all cigarette brands in Vietnam started to be printed with graphic health warnings". Since August 08, 2013, six GHW designs, covering 50\% surface of both sides of the pack, started being printed on cigarette packages. The GHW designs are expected to be changed every two years. The WHO classified Vietnam as a country who reached the highest achievement on health warnings - a component of the MPOWER intervention strategy (World Health Organization, 2015).

More than one year after implementation of the graphic health warning intervention in Vietnam, it is very important to evaluate the intervention's potential impact. The objective of the presetn research was to predict the potential impact of graphic health warnings on cigarette package on cigarette demand and smokingassociated deaths in Vietnam. This research should assist in preparation of GHW design improvements and help advocate for stronger tobacco prevention and control policies in Vietnam. 


\section{Materials and Methods}

In this study, a discrete choice experiment (DCE) method was used to evaluate the potential impact of graphic tobacco health warnings on the reduction of smoking demand. DCE is a quantitative technique for eliciting individual preferences for attributes of a product, a service, or an intervention. A typical DCE study allows researchers to uncover how much individuals attribute value to a product (or an intervention, as in our proposed study) and to estimate marginal values (or willingness to pay) of attributes (Mangham et al., 2009). DCE has also been used in health economics (Mangham et al., 2009) as well as in some tobacco research (Thrasher et al., 2011).

We selected four GHW designs that have been used in Vietnam for this study, including 1) graphic image of lung damage; 2) graphic image of human suffering; 3 ) graphic image of abstract damage; and 4) graphic image of damaged teeth. All the GHWs cover 50\% of the lower half of the front and back of the cigarette package. The text only design, covering $30 \%$ of the lower half of the front and back of the cigarette package, was used for comparison (Figure 1).

The DCE exercise was conducted in two rounds (in June 2014 and January 2015). In each round, 2634 participants aged 15 years and over were studied. This sample size was estimated based on the guide by Johnson FR et al. (Reed Johnson et al., 2013). We identified three region-based stratifications (the north, the central region, and the south). In each selected region, communes (primary sampling units-PSUs) were classified into 4 groups based on living area (urban vs. rural areas) and economic situation (poor vs. non-poor communes). For example, we had 4 lists of communes: 1) urban poor; 2) urban non-poor; 3) rural poor and 4) rural non-poor communes. Five communes were randomly selected from each list (type) of commune (a total of 20 communes were selected in each region) (Figure 2).

The selected study subjects answered the DCE questionnaire eliciting their preferences for not buying cigarette packs based on their responses to the choice sets showing different formats of warning labels on cigarette packages. Response to the choice question could be buying cigarette Pack A, or buying cigarette pack B, or neither. The data were collected via in-person interviews.

The DCE data were analyzed using a conditional logit model. Response to the choice question (i.e., buying cigarette Pack A, or buying cigarette pack B, or neither) was the dependent variable. With effects coding, zero indicates the mean effect across all attribute levels, rather than the omitted attribute level, as in dummy coding (Hensher DA et al., 2005). This procedure produces a coefficient for all attribute levels, where the coefficient for the omitted attribute level is the negative sum of those for the included attribute levels. The resulting coefficients can be interpreted as preference weights, where $t$-statistic values indicate whether preference weights differ significantly from zero (i.e., the mean effect), not from an omitted attribute level. Also, middle attribute levels often are close to the mean effect, and thus will have low significance. If the confidence intervals (calculated at the $95 \%$ level) around any two preference weights did not overlap, the differences between the preference weights were statistically significant at the $5 \%$ level or better $(\mathrm{P} \leq 0.05)$. These analyses were carried out by using statistical software Stata 12.

Using the conditional logit model, the probability of buying cigarette packages with GHW can be imputed

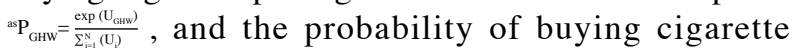
packages with health warning in text only can be imputed

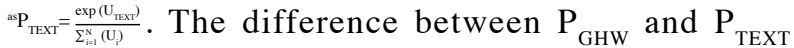
indicates the predicted reduction in demand for cigarettes when switching from text only health warnings to graphic health warnings.

To predict the impact of GHWs on the reduction of premature smoking-associated deaths as a result of GHWs, we constructed different static models. We adapted the method developed by University of Toronto, Canada (Used in the research "Tobacco Taxes: A Win-Win Measure for Fiscal Space and Health"(Asian Development Bank, 2013)). We evaluated the impact of different GHW labels on cigarette packaging on reducing the number of smokers. The reduction in the number of smokers was then converted into prevented smoking-related mortality. The prediction exercise was conducted in two steps. The parameters and assumptions used in the prediction are

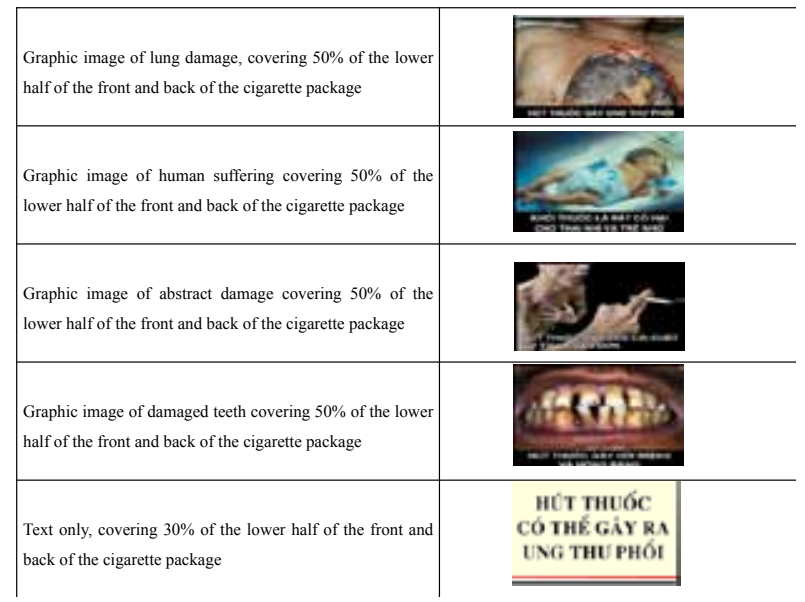

Figure 1. GHW Designs Used in this Study

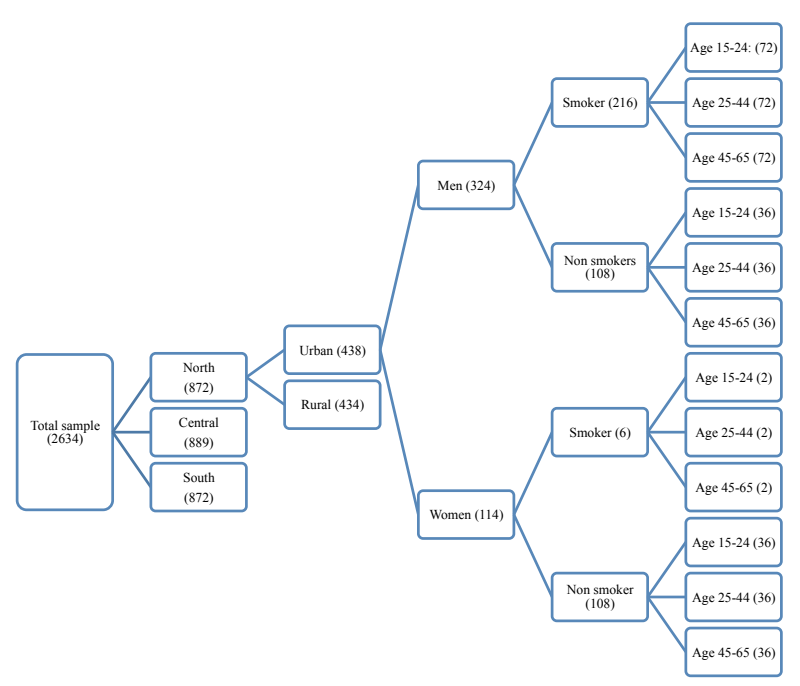

Figure 2. Study Sample Illustration 
Predicting Impact of Graphic Health Warnings on Reducing Cigarette Demand and Smoking-Related Deaths in Vietnam

presented in Table 1.

Step 1: The reduction in the number of smokers because of a GHW was a product of the (i) original number of smokers in each age and sex group (male, female, aged 15-24, 25-44, and 45 and above) (ii) reduction in cigarette demand because of each GHW (generated through our DCE method).

Reduction in the Number Of Smokers= Original Number of Smokers* (1-\% Reduction in Cigarette Demand Because of Graphic Health Warning)

The original number of smokers in each age and sex group (male, female, aged 15-24, 25-44, and 45 and above) were estimated by data from the population information gathered from the latest Census in Vietnam and the Vietnam Global Adult Tobacco Survey (GATS) 2010. The future adult smoking prevalence of youth already alive but not yet smoking (those currently under the age of 15) was assumed to be the current prevalence rate for the age group at which smoking rates peak (30-44 years) in the GATS data(Ministry of Health and Vinacosh, 2011). Our model assumed that there is no additional initiation among those 15 years and older. This was a conservative approach as the prevalence for those 15-29 years old was likely to rise, as research in India has shown that there is a peak for those 30-44 (Asian Development Bank, 2013).

Step 2: The number of premature tobacco-related deaths avoided as a result of a GHW was the product of the (i) the reduction in the number of smokers because of a GHW and (ii) Attributable fraction (AF) of tobacco related mortality among smokers.

Reduction in the Number of Premature TobaccoRelated Deaths=Reduction in the Number of Smokers * Attributable Fraction for Tobacco Related Mortality

We assumed that half of all regular cigarette smokers will eventually die from smoking-related illnesses (Asian Development Bank, 2013). Quitting confers benefits;

Table 1. Parameters and Assumptions Used in the Prediction

\begin{tabular}{lccc}
\hline \multicolumn{1}{c}{ Parameters } & Male & Female & Data source \\
\hline Baseline number of cigarette smokers & $12,426,100$ & 397,200 & Vietnam GATS 2010 \\
Prevalence of cigarette smoking & $39.7 \%$ & $1.2 \%$ & 75,000 \\
Youth future smokers & $5,649,000$ & $50 \%$ & Method developed by University of \\
Cigarette mortality & $50 \%$ & $80 \%$ & Toronto, Canada, 2013 \\
Percent avoiding premature death among those & $80 \%$ & $50 \%$ & $50 \%$ \\
who quit & & & \\
Proportion who quit & &
\end{tabular}

Table 2. Reduction in Demand for Cigarettes when Changing from Old to New Health Warning Labels (among Smokers)

\begin{tabular}{|c|c|c|c|c|}
\hline & \multicolumn{2}{|c|}{ Round 1} & \multicolumn{2}{|c|}{ Round 2} \\
\hline & $\begin{array}{l}\text { Probability } \\
\text { of purchase }\end{array}$ & $\begin{array}{l}95 \% \text { Confidence } \\
\text { Intervals }\end{array}$ & $\begin{array}{l}\text { Probability } \\
\text { of purchase }\end{array}$ & $\begin{array}{l}\text { 95\% Confidence } \\
\text { Intervals }\end{array}$ \\
\hline $\begin{array}{l}\text { Old health warning label (text only design, covering } 30 \% \\
\text { of the lower half of the front and back of the cigarette } \\
\text { package) }\end{array}$ & 0.981 & $0.977-0.984$ & 0.983 & $0.979-0.987$ \\
\hline $\begin{array}{l}\text { New health warning label } 1 \text { (graphic image of lung dam- } \\
\text { age, covering } 50 \% \text { of the lower half of the front and back } \\
\text { of the cigarette package) }\end{array}$ & 0.881 & $0.857-0.901$ & 0.882 & $0.856-0.904$ \\
\hline $\begin{array}{l}\text { Reduction in demand for cigarettes when changing from } \\
\text { old to new health warning label } 1\end{array}$ & -0.1 & $-0.121--0.082$ & -0.101 & $-0.124--0.082$ \\
\hline $\begin{array}{l}\text { New health warning label } 2 \text { (graphic image of human } \\
\text { suffering, covering } 50 \% \text { of the lower half of the front and } \\
\text { back of the cigarette package) }\end{array}$ & 0.932 & $0.918-0.944$ & 0.938 & $0.923-0.95$ \\
\hline $\begin{array}{l}\text { Reduction in demand for cigarettes when changing from } \\
\text { old to New health warning label } 2\end{array}$ & -0.049 & $-0.06--0.039$ & -0.046 & $-0.057--0.036$ \\
\hline $\begin{array}{l}\text { New health warning label } 3 \text { (graphic image of abstract } \\
\text { damage, covering } 50 \% \text { of the lower half of the front and } \\
\text { back of the cigarette package) }\end{array}$ & 0.939 & $0.926-0.95$ & 0.945 & $0.933-0.956$ \\
\hline $\begin{array}{l}\text { Reduction in demand for cigarettes when changing from } \\
\text { old to New health warning label } 3\end{array}$ & -0.042 & $-0.051--0.033$ & -0.038 & $-0.047--0.03$ \\
\hline $\begin{array}{l}\text { New health warning label } 3 \text { (graphic image of teeth dam- } \\
\text { age, covering } 50 \% \text { of the lower half of the front and back } \\
\text { of the cigarette package) }\end{array}$ & 0.943 & $0.93-0.953$ & 0.941 & $0.928-0.953$ \\
\hline $\begin{array}{l}\text { Reduction in demand for cigarettes when changing from } \\
\text { old to new health warning label } 4\end{array}$ & -0.038 & $-0.047--0.03$ & -0.042 & $-0.052--0.033$ \\
\hline
\end{tabular}


Table 3. Increasing in Probability of Not Buying Cigarette When Changing from Old to New Health Warning Labels (among Non-Smokers)

\begin{tabular}{|c|c|c|c|c|}
\hline & \multicolumn{2}{|c|}{ ROUND 1} & \multicolumn{2}{|c|}{ ROUND 2} \\
\hline & $\begin{array}{l}\text { Probability of } \\
\text { non-purchase }\end{array}$ & $\begin{array}{l}95 \% \text { Confidence } \\
\text { Intervals }(\%)\end{array}$ & $\begin{array}{l}\text { Probability of } \\
\text { non-purchase }\end{array}$ & $\begin{array}{l}95 \% \text { Confidence } \\
\text { Intervals }(\%)\end{array}$ \\
\hline $\begin{array}{l}\text { Old health warning label (text only design, covering } \\
30 \% \text { of the lower half of the front and back of the } \\
\text { cigarette package) }\end{array}$ & $86.8 \%$ & $81.4-91.1$ & $80.3 \%$ & $75.1-84.8$ \\
\hline $\begin{array}{l}\text { New health warning label } 1 \text { (graphic image of lung } \\
\text { damage, covering } 50 \% \text { of the lower half of the front } \\
\text { and back of the cigarette package) }\end{array}$ & $99.0 \%$ & $98.6-99.4$ & $98.1 \%$ & $97.4-98.6$ \\
\hline $\begin{array}{l}\text { Reduction in demand for cigarettes when changing } \\
\text { from old to New health warning label } 1\end{array}$ & $12.2 \%$ & $8.3-17.1$ & $17.8 \%$ & $13.7-22.4$ \\
\hline $\begin{array}{l}\text { New health warning label } 2 \text { (graphic image of hu- } \\
\text { man suffering, covering } 50 \% \text { of the lower half of the } \\
\text { front and back of the cigarette package) }\end{array}$ & $97.8 \%$ & $96.7-98.6$ & $96.0 \%$ & $94.7-97.1$ \\
\hline $\begin{array}{l}\text { Reduction in demand for cigarettes when changing } \\
\text { from old to New health warning label } 2\end{array}$ & $11.0 \%$ & $7.4-15.4$ & $15.80 \%$ & $12.2-19.8$ \\
\hline $\begin{array}{l}\text { New health warning label } 3 \text { (graphic image of ab- } \\
\text { stract damage, covering } 50 \% \text { of the lower half of the } \\
\text { front and back of the cigarette package) }\end{array}$ & $97.8 \%$ & $96.7-98.6$ & $95.1 \%$ & $93.5-96.4$ \\
\hline $\begin{array}{l}\text { Reduction in demand for cigarettes when changing } \\
\text { from old to New health warning label } 3\end{array}$ & $11.0 \%$ & $7.4-15.4$ & $14.80 \%$ & $11.4-18.7$ \\
\hline $\begin{array}{l}\text { New health warning label } 3 \text { (graphic image of teeth } \\
\text { damage, covering } 50 \% \text { of the lower half of the front } \\
\text { and back of the cigarette package) }\end{array}$ & $97.8 \%$ & $96.7-98.6$ & $94.3 \%$ & $92.5-95.8$ \\
\hline $\begin{array}{l}\text { Reduction in demand for cigarettes when changing } \\
\text { from old to New health warning label } 4\end{array}$ & $11.0 \%$ & $7.4-15.40 \%$ & $14.1 \%$ & $10.8-17.7$ \\
\hline
\end{tabular}

Table 4. Potential Impact of GHWs on Reduction of Disease Burden (Premature Deaths Avoided)

\begin{tabular}{|c|c|c|c|c|c|c|c|c|}
\hline \multirow[t]{2}{*}{ Indicators } & \multicolumn{2}{|c|}{$\begin{array}{l}\text { Image of lung } \\
\text { damage }\end{array}$} & \multicolumn{2}{|c|}{$\begin{array}{l}\text { Image of human } \\
\text { suffering }\end{array}$} & \multicolumn{2}{|c|}{$\begin{array}{l}\text { Image of abstract } \\
\text { damage }\end{array}$} & \multicolumn{2}{|c|}{$\begin{array}{l}\text { Image of teeth } \\
\text { damage }\end{array}$} \\
\hline & Round 1 & Round 2 & Round 1 & Round 2 & Round 1 & Round 2 & Round 1 & Round 2 \\
\hline $\begin{array}{l}\text { Reduction in premature deaths } \\
\text { among adults who quit smoking }\end{array}$ & 96,720 & 100,056 & 46,424 & 41,534 & 39,477 & 33,646 & 36,536 & 37,576 \\
\hline $\begin{array}{l}\text { Reduction in smoking deaths among } \\
\text { youth prevented from starting } \\
\text { smoking }\end{array}$ & 477,104 & 546,042 & 414,777 & 469,143 & 411,840 & 468,581 & 391,881 & 391,881 \\
\hline $\begin{array}{l}\text { Total number of premature deaths } \\
\text { avoided }\end{array}$ & 573,823 & 646,098 & 461,201 & 510,677 & 451,317 & 502,227 & 428,417 & 429,457 \\
\hline
\end{tabular}

the longer one has quit, the greater the accrual of these benefits. We assumed that the overall reduction in risk for premature death avoided was $80 \%$ of those who were nonsmokers(Asian Development Bank, 2013).A systematic literature review of latest relevant research evidence (especially on Attributable fraction (AF) of getting tobacco-related morbidity and mortality among smokers) and expert consultation were conducted to develop assumptions and scenarios for our model estimation. These projection and modeling exercises were carried out in Excel.

\section{Ethical considerations}

This research was reviewed and approved by the Scientific and Ethics Committee of the Hanoi Medical University. Before participating in this study, all invited respondents were provided with information regarding this research. They were informed that participation would be voluntary followed by providing the informed consent.
Their responses were kept confidential. There would be no right or wrong answers. Participants could voluntarily stop or withdraw from the study at any time; and refusal or withdrawal would not have any effect or consequences.

\section{Results}

Table 2 presents the potential impacts of different GHW labels (i.e. the four among 6 design currently being used in Vietnam) on the reduction in tobacco demands among smokers as compared to the old health warning design (text only, covering $30 \%$ of the lower half of the front and back of the cigarette package). GHWs were found to reduce demand for cigarettes among smokers from $3.8 \%$ to $10 \%$ in survey round 1 and from $4.2 \%$ to $10.1 \%$ in survey round 2 . For smokers, the graphic image of lung damage, covering $50 \%$ of the lower half of the front and back of the cigarette package, was shown to have the strongest impact on reducing smoking demand 
Predicting Impact of Graphic Health Warnings on Reducing Cigarette Demand and Smoking-Related Deaths in Vietnam

Table 5. Potential Impact of GHWs on Reduction of Disease Burden and Premature Deaths Avoided by Living Location

\begin{tabular}{ccccccccc}
\hline \multirow{2}{*}{ Indicators } & \multicolumn{2}{c}{ Image of lung damage } & \multicolumn{2}{c}{ Image of human suffering } & \multicolumn{2}{c}{ Image of abstract damage } & \multicolumn{3}{c}{ Image of teeth damage } \\
\cline { 2 - 9 } & Rural & Urban & Rural & Urban & Rural & Urban & Rural & Urban \\
\hline Round 1 & 375,313 & 198,510 & 301,684 & 159,517 & 295,207 & 156,110 & 280,223 & 148,194 \\
Round 2 & 423,856 & 222,242 & 334,399 & 176,278 & 328,816 & 173,411 & 280,908 & 148,549 \\
\hline
\end{tabular}

Table 6. Potential Impact of GHWs on Reduction of Disease Burden (Premature Deaths Avoided) by Living Economic Status (Income Quintile)

\begin{tabular}{lccccc}
\hline \multicolumn{1}{c}{$\begin{array}{c}\text { Image } \\
\text { Image of lung damage }\end{array}$} & Quintile 1 & Quintile 2 & Quintile 3 & Quintile 4 & Quintile 5 \\
$\quad$ Round 1 & 125,544 & 128,339 & 103,662 & 120,544 & 95,761 \\
$\quad$ Round 2 & 143,118 & 143,118 & 116,708 & 135,839 & 106,498 \\
Image of human suffering & & & & \\
$\quad$ Round 1 & 101,006 & 103,114 & 83,316 & 96,859 & 76,924 \\
$\quad$ Round 2 & 112,934 & 113,794 & 92,251 & 106,987 & 84,736 \\
Image of abstract damage & & & & \\
Round 1 & 98,805 & 100,917 & 81,531 & 94,786 & 75,289 \\
$\quad$ Round 2 & 110,910 & 111,965 & 90,725 & 105,254 & 83,396 \\
Image of teeth damage & & & & \\
Round 1 & 93,774 & 95,803 & 77,394 & 89,983 & 71,476 \\
Round 2 & 94,018 & 96,029 & 77,582 & 90,204 & 71,645 \\
\hline
\end{tabular}

among the smokers $(10 \%, 95 \% \mathrm{CI}$ from $8.2 \%$ to $12.1 \%$ in survey round 1 ; and $10,1 \%, 95 \mathrm{CI}$ from $8.2 \%$ to $12, .4 \%$ in survey round 2).

As shown in Table 3, the predicted increase in probabilities of not buying cigarettes among non-smokers when switching from text only health warning to graphic health warnings ranges from $11 \%$ to $17.1 \%$ in survey round 1 and from $14.1 \%$ to $17.8 \%$ in survey round 2 . For non-smokers, the graphic image of lung damage, covering $50 \%$ of the lower half of the front and back of the cigarette package, was also shown to have the most significant impact on preventing participants from smoking initiation $(12.2 \%, 95 \% \mathrm{CI}$ from $8.3 \%$ to $17.1 \%$ in survey round 1 ; and $17.8 \% ; 95 \% \mathrm{CI}$ from $13.7 \%$ to $22.4 \%$ in survey round 2).

Table 4 illustrates the potential impact of the GHW labels on reducing premature smoking-associated deaths in Vietnam. Between 428,417-646,098 premature deaths would be prevented as a result of the GHW intervention. The graphic image of lung damage had the strongest impact, followed by the image of human suffering, image of abstract damage and image of teeth damage. For all kinds of GHW labels included in our study, the impact was stronger after one year of implementation (survey round 2).

The potential impact of the GHW labels on reduction of premature smoking-associated deaths in Vietnam by living location and economic status of the study subjects are presented in table 5 and table 6 , respectively. More premature deaths were avoided among rural habitants as compared to those living in urban areas. For example, the potential premature deaths avoided as a result of GHW with lung damage picture among the rural and urban populations were 423,856 and 222,242 , respectively (Table 4). Stronger impact of GHWs was also found among poorer people. For example, the potential premature deaths avoided as a result of GHW with the image of lung damage among the lowest and the highest income quintiles were 143,118 and 106,498, respectively.

\section{Discussion}

This study adds to the existing literature by using discrete choice experiment (DCE) method to predict potential impact of graphic health warnings on cigarette package on reduction in cigarette demand and smokingassociated deaths in Vietnam.

We found that GHWs had statistically significant impact on reducing cigarette demand (up to 10\%,1), resulting in decreased smoking prevalence in Vietnam. This finding is in line with the previous research about the effect of new graphic health warning labels on reducing tobacco consumption compared with the old text only health warning labels (O'Hegarty et al.,, 2006; Borland et al., 2009; Shanahan et al., 2009; Cantrell et al., 2013). GHWs are clearly effective in informing consumers about the risks of smoking and discouraging smoking (Hammond, 2011). A study conducted in Mexico found that packing with graphic images had a mean attributed value which was $17 \%$ lower than the text-only packages (Thrasher et al., 2011). Using nationally representative data on smoking among persons 15 years and older from the Canadian National Population Health Surveys conducted between 1998 until 2008, Azagba and Sharaf estimate that smoking prevalence in Canada fell by $12.5 \%$ as a result of that country's GWLs (Azagba and Sharaf, 2013). Another study, also from Canada, found that adopting GWLs on cigarette packages reduced smoking prevalence, reduced smoking rates by $2.87-4.68$ percentage points, a relative reduction of 12.1-19.6\% (Huang et al., 2014).

In our study, the graphic image of lung damage was shown to have the strongest impact on reducing cigarette 
demand. This is similar to the findings from a Mexico study, which reports GHW about lung disease and cancer generated the strongest motivation to quit (Mays et al., 2015).

We also found that between 428,417-646,098 premature deaths would be prevented as a result of the GHW intervention. A study in Asia, using the same method, projected that, a $50 \%$ price increase, corresponding to a tax increase of about $70 \%-122 \%$, would reduce the number of tobacco deaths by 992,000 million(Asian Development Bank, 2013). A study from Canada estimated that GHWs would result in nearly 5,000 fewer deaths annually among non-smokers in the country (Huang et al., 2014).

In our study, the potential impacts of the GHW labels on reducing premature smoking-related deaths in Vietnam were shown to be stronger among lower socio-economic groups (i.e. rural dwellers and poorer populations). Similar findings reported by a US study showed that labels designed to increase risk perceptions from smoking might be significant sources of motivation for low SES smokers (Mead et al., 2015). Hammond et al. (2012) found that graphic depictions of disease were perceived by youth and adults as the most effective warning theme. Perceptions of warnings were generally similar across socio-demographic groups. Cantrell at el. (2013) also found the effects of graphic health warning labels were consistent across sub-population groups regardless of their different socio-characteristics in our study.

In conclusion, this study adds to the growing body of evidence on the impacts of GHWs. Our findings suggest that GHWs had significant impact on reducing cigarette demand and smoking-associated deaths in Vietnam. GHWs also have impact on reducing health inequity in Vietnam.

Due to budget and technical constraints, we only evaluated the impact of 4 among 6 current GHW available on the market. Our model for predicting the impact of GHWs on the reduction of premature smoking-associated deaths are simple and static, which yield conservative estimates. Further research on the impact of GHWs labels with longer periods of time and using more sophisticated models could provide greater information and evidence for policy advocacy and implementation.

\section{Acknowledgements}

We thank International Development Research Centre (IDRC) for providing funding support for this study. We also would like to express our sincere appreciation to Dr. Malcolm Moore, the Editor-in-Chief of the Asian Pacific Journal of Cancer prevention, for his significant input to this paper. We further are indebted to Viet Nguyen from Harvard Medical School for editing the English of this paper.

\section{References}

Asian Development Bank (2013). Tobacco Taxes: A Win-Win Measure for Fiscal Space and Health.

Azagba S, Sharaf MF (2013). The effect of graphic cigarette warning labels on smoking behavior: evidence from the
Canadian experience. Nicotine Tob Res, 15, 708-17.

Borland R YH, Wilson N, Fong GT, Hammond D (2009). How reactions to cigarette packet health warnings influence quitting: findings from the ITC Four-Country survey. Addiction, 104, 669-75.

Hammond D (2011). Health warning messages on tobacco products: a review. Tob Control, 20, 327-37.

Hammond D, Thrasher J, Reid JL, et al (2012). Perceived effectiveness of pictorial health warnings among Mexican youth and adults: a population-level intervention with potential to reduce tobacco-related inequities. Cancer Causes Control, 23, 57-67.

Hensher DA, Rose JM, Greene WH (2005). Applied choice analysis. Cambridge: Cambridge University Press.

Huang J, Chaloupka FJ, Fong GT (2014). Cigarette graphic warning labels and smoking prevalence in Canada: a critical examination and reformulation of the FDA regulatory impact analysis. Tob Control, 23, 7-12.

Cantrell J, Thrasher JF, Nagler RH, et al (2013). Impact of Tobacco-Related Health Warning Labels across Socioeconomic, Race and Ethnic Groups: Results from a Randomized Web-Based Experiment. PLoS One.

Mangham LJ, Hanson K, McPake B (2009). How to do (or not to do) ... Designing a discrete choice experiment for application in a low-income country. Health Policy Plan, 24, 151-8.

Mays D, Niaura RS, Evans WD, et al (2015). Cigarette packaging and health warnings: the impact of plain packaging and message framing on young smokers. Tob Control, 24, 87-92.

Mead EL, Cohen JE, Kennedy CE, et al (2015). The role of theory-driven graphic warning labels in motivation to quit: a qualitative study on perceptions from low-income, urban smokers. BMC Public Health, 15, 92.

O'Hegarty M, Nelson DE, Mowery P, Gable JG, Wortley P (2006). Reactions of young adult smokers to warning labels on cigarette packages. Am J Prev Med.

Ministry of Health, Vinacosh (2011). Global Tobacco Use Survey (GATS) Vietnam 2010.

Reed Johnson F, Lancsar E, Marshall D, et al (2013). Constructing experimental designs for discrete-choice experiments: report of the ISPOR Conjoint Analysis Experimental Design Good Research Practices Task Force. Value Health, 16, 3-13.

Shanahan PED (2009). Evaluation of the effectiveness of graphic health warnings on tobacco product packaging 2008- executive summary,. australian department of health and ageing.

Thrasher JF, Rousu MC, Hammond D, et al (2011). Estimating the impact of pictorial health warnings and "plain" cigarette packaging: evidence from experimental auctions among adult smokers in the United States. Health Policy, 102, 41-8. 